\section{MORE ON SARS AND THE EVIDENCE BASE FOR PUBLIC HEALTH}

In this issue we have a final commentary on the debate about the return of SARS and three papers covering various aspects of the epidemic: Syed and colleagues report on their experience of travelling in the SARS zones during the outbreak and their perception, as travellers, of the measures taken; Leung and colleagues, from Hong Kong, report on the impact of community psychological response on personal preventive measures taken; while Lau provides data on the perceptions and behaviours as they evolved.

\section{See pages $840,855,857,864$}

With such a classical infectious disease model in mind, Speaker's Corner directs our attention to the limitations of the communicable disease paradigm when faced with many non-microbial diseases, but which have contagious aspects to them relating to lifestyle and behaviour.

\section{See page 838}

The recent theft of a Picasso painting from a Manchester art gallery prompts one of our contributors to explore the portrayal of poverty in art, and also in this month's Gallery a Belgian female

\section{www.jech.com}

occupational health pioneer is given suitable recognition.

\section{See pages 839,843}

From our Evidence Based Public Health Policy and Practice section:

- Returning to the theme of evidence, Tang and an international group of collaborators, explore the options available to put health promotion on a proper evidence base and propose a classification of typologies.

- From Chile comes an exploration of income inequality and health, concluding that household income does not explain between community differences.

- D'Souza, from Australia, concludes that in a relatively privileged socioeconomic group insecure employment and high job strain showed independent, consistent, and strong associations with physical and mental health.

\section{See pages $841,844,849$}

Research Reports include:

- From London, a finding that among 13 to 14 year old school students from south east England, those disliking school were more likely to have sexual intercourse and be parents by the age of 20 .

- From Sweden, foreign born and second generation women of child bearing age had a higher risk than Swedish born women for a first psychiatric hospital admission.

- A highly topical study of Crohn's disease, ulcerative colitis and measles vaccine in an English population from 1979 to 1998 provides strong evidence against measles vaccine causing Crohn's disease or ulcerative colitis.

- And a prospective observational study from France finds that early markers of adult psychological distress are associated with increased mortality from various causes.

See pages $871,877,883,901$

Titbits from Hygieia include some factual data on the actual levels of tuberculosis in asylum seekers, an update on the environmental health impact of the Montserrat volcanic eruption of 1995, and a lack of evidence to support a strong relation between alcohol misuse and pancreatic cancer. The phenomenon of our aging population and its implications for one type of later life disability, blindness, is brought out in a paper reprinted from the British Journal of Ophthalmology, and finally, the fact that inequity gets everywhere is illustrated by the finding that elderly people, smokers and those who have had angina but not a heart attack are all less likely to receive the cholesterol lowering statins.

See page 915 